\title{
Atlantis
}

Critical Studies in Gender, Culture \& Social Justice

Études critiques sur le genre, la culture, et la justice

\section{Troubling Diversity and Inclusion: Racialized Women's Experiences in the Canadian Armed Forces}

\section{Tammy George}

Volume 41, Number 2, 2020

Gender and the Canadian Armed Forces

URI: https://id.erudit.org/iderudit/1076199ar

DOI: https://doi.org/10.7202/1076199ar

See table of contents

Publisher(s)

Mount Saint Vincent University

ISSN

1715-0698 (digital)

Explore this journal

Cite this article

George, T. (2020). Troubling Diversity and Inclusion: Racialized Women's Experiences in the Canadian Armed Forces. Atlantis, 41(2), 42-56. https://doi.org/10.7202/1076199ar

\section{Article abstract}

This article centers on the lived experiences of racialized servicewomen in the Canadian Armed Forces (CAF). Drawing on qualitative interviews with racialized servicewomen, I problematize the function of contemporary diversity and inclusion initiatives within the CAF. Focusing on the intersection of race and gender in their lives provides a way to think through structural inequities within the Canadian military. By examining how these structures of power operate within the CAF, we are better situated to understand how current diversity and inclusion initiatives work to consolidate hegemonic power. Informed by feminist critical race theories and critical geography, I trace the experiences of racialized servicewomen to understand how they make sense of their inclusion and belonging and how they assess their everyday experiences in the context of diversity and inclusion strategies presented by the CAF. Their lived experiences reveal the importance of race and gender in their lives, and expose the limits of diversity and inclusion practices, particularly, in their inability to address deeper structural issues of white supremacy, heteronormativity, and patriarchy within the CAF. While concepts of diversity and inclusion are typically concerned with the inclusion of those on the margins, this research suggests that we must seriously interrogate the theoretical, practical, and political work of diversity and inclusion initiatives within a multicultural context. Troubling inclusion and diversity in the CAF demands we disrupt structures of dominance and reflect on how to re/conceptualize and re/integrate meaningful difference more substantially throughout institutional life in multicultural Canada.
This document is protected by copyright law. Use of the services of Erudit (including reproduction) is subject to its terms and conditions, which can be viewed online.

https://apropos.erudit.org/en/users/policy-on-use/ 


\section{Troubling Diversity and Inclusion: Racialized Women's Experiences in the Canadian Armed Forces}

Tammy George is an assistant professor in the Faculty of Health Science, School of Kinesiology in the area of Critical Socio-Cultural \& Policy Studies in Sport \& Physical Activity at York University. She is an interdisciplinary scholar whose current research lies at the intersection of mental health, critical military studies, feminist theory, and racial violence.

Abstract: This article centers on the lived experiences of racialized servicewomen in the Canadian Armed Forces (CAF). Drawing on qualitative interviews with racialized servicewomen, I problematize the function of contemporary diversity and inclusion initiatives within the CAF. Focusing on the intersection of race and gender in their lives provides a way to think through structural inequities within the Canadian military. By examining how these structures of power operate within the CAF, we are better situated to understand how current diversity and inclusion initiatives work to consolidate hegemonic power. Informed by feminist critical race theories and critical geography, I trace the experiences of racialized servicewomen to understand how they make sense of their inclusion and belonging and how they assess their everyday experiences in the context of diversity and inclusion strategies presented by the CAF. Their lived experiences reveal the importance of race and gender in their lives, and expose the limits of diversity and inclusion practices, particularly, in their inability to address deeper structural issues of white supremacy, heteronormativity, and patriarchy within the CAF. While concepts of diversity and inclusion are typically concerned with the inclusion of those on the margins, this research suggests that we must seriously interrogate the theoretical, practical, and political work of diversity and inclusion initiatives within a multicultural context. Troubling inclusion and diversity initiatives in the CAF demands we disrupt structures of dominance and reflect on how to re/ conceptualize and re/integrate meaningful difference more substantially throughout institutional life in multicultural Canada.

Keywords: Canadian Armed Forces, diversity and inclusion, gender, intersectionality, race 
Tn response to increasing demographic changes 1 within Canadian society, the question of diversity politics has plagued institutional life in the contemporary moment. The Canadian Armed Forces (CAF) is no exception. The 2016 Canadian Armed Forces Diversity Strategy, the CAF's guiding document and policy on diversity and inclusion, includes strong language on improving issues of representation, cultural sensitivity, and discrimination in the workplace. It defines diversity as "respect for and appreciation of differences in ethnicity, language, gender, age, national origin, disabilities, sexual orientation, education and religion. It is about understanding each other and moving beyond simple tolerance to embracing, celebrating, and integrating the rich dimension of diversity within each individual" (Chief of Defence Staff 2016, 1). While this definition does offer possibilities to think through the complexity of identity at the individual level, the CAF has failed to implement a diversity strategy that is attentive to overlapping marginalities and instead has focussed on the siloed nature of diversity. Goals towards inclusion have been largely about representation and demographic shifts rather than centering on the muchneeded cultural shift or the lived experiences among marginalized servicemen and servicewomen.

In what follows, I draw on qualitative interviews with racialized servicewomen to problematize and challenge the function of diversity and inclusion initiatives within the CAF. Focusing on the intersection of race and gender in women's lives provides a way to think through what bell hooks (2006) refers to as, the "imperial, white supremacist, heteropatriarchal" structure of institutional life (60). By examining how these structures of power operate within the CAF, we are better situated to understand how current diversity and inclusion initiatives work to consolidate hegemonic power. I draw on the lived experiences of racialized servicewomen to understand how they make sense of their inclusion and belonging and how they assess their everyday experiences in the context of diversity and inclusion strategies put forth by the CAF. Their lived experiences reveal the saliency of race and gender as constitutive in their everyday lives, and expose the limits of diversity and inclusion prac- tices, particularly, in their inability to address deeper structural issues of white supremacy, heteronormativity, and patriarchy within the CAF. The implications of this research suggest that we must seriously interrogate the theoretical, practical, and political work of diversity and inclusion pursuits within a multicultural context. Additionally, thinking through the figure of the racialized servicewoman who at present is both target and agent of gendered and racial violence on the home front and in theatres of war deserves our attention.

Typically, research on soldiers does not take into consideration the intersections of identities. While scholarship on intersectionality is a growing area within the field of gender and International Relations, intersectionality as a concept has been absent in studies of military personnel and military sociology which are often concerned with stratification and hierarchies within military organizations (Henry 2017). Although there has been ample research and scholarly work on race and gender as separate entities in the military from a variety of perspectives (i.e. racial patterns in enlistment, officer promotion rates, administration of military justice, risk of death in combat, and health care for wounded soldiers), particularly in the American context, very little academic scholarship in Canada has brought together various bodies of work centering on the lived experience of racialized servicewomen and how they negotiate national belonging within the Canadian multicultural context. Literature on war and soldiering has largely dealt with markers of identity such as race, gender, and sexuality as characteristics, attributes, and/or separate entities, rather than focussed on the practices of racialization and gendering as they are produced institutionally and lived out on a daily basis (Henry 2017; Ito 1984; Roy 1978; Walker 1989; Ware 2012).

The focus on racialized women is important because they are a largely neglected subpopulation as diversity initiatives in the CAF tend to be siloed or focused on singular markers of identity (i.e. race or gender or sexuality or Indigeneity). My research fills a void within the military literature by developing an intersectional analysis (Crenshaw 1991) specifically cen- 
tering on race and gender. Furthermore, understanding racialized servicewomen's experiences makes an important contribution toward understanding how intersecting identities and systems of power inform the everyday experiences and the institutional culture of the CAF. The role and lived experience of racialized servicewomen within a multicultural framework is a key component to the making of the Canadian racial state and articulations of citizenship.

This article is organized as follows: first, I unpack how institutional racism and whiteness operate in the $\mathrm{Ca}$ nadian context and how they are currently embedded through certain components of neoliberal policy and ethos. These theoretical underpinnings serve to ground and explain the data presented. The first data section examines how racialized women see themselves within the military institution and how their intersecting identities coincide with the ethos of the military soldier. Next, I expand on how the white male gaze is experienced and how institutional whiteness is consolidated within the CAF. I explore how racial neoliberalism manifests itself within the CAF often through a culture of silence, pointing to the limits of diversity and inclusion initiatives. Finally, the significance and implications for racialized servicewomen within the CAF are discussed, suggesting that while diversity and inclusion initiatives may sensitize us to individual differences, they do little to challenge existing relations of power.

\section{Understanding Institutional Racism and Whiteness in Canada ${ }^{1}$}

Central to this research study is understanding how white supremacy and racism operate institutionally within the CAF. Critical race scholars have critiqued the state's role in racist and/or exclusionary acts (Bannerji 2000; Razack 2004; Thobani 2007) to show how racism operates both historically and into the present day. Drawing on these scholars, I was able to trace the connections between the state and racial exclusions and examine how they manifest conceptually, theoretically, materially, and spatially. Patricia Price (2010) addresses the intersection among embedded structures of whiteness through critical race theory, as well as how whiteness is embodied using critical geographies of race. Before we can attempt to negate racialized discourses, we must understand how deeply structured and embedded white supremacy is in our colonial histories, economic institutions, and political structures and how this embeddedness continues to have an impact on the present.

Several scholars have documented how the existence of racism in Canadian society is grounded in different historical events involving racialized groups in Canada. They have further examined how these encounters with racism operate institutionally (Bannerji 2000; Mensah 2010; Razack 2002; Thobani 2007). For example, Himani Bannerji (2000) argues that the labour market acts as a barrier for racialized individuals because Canada itself is constructed as a "white" nation, thereby discriminating against racialized bodies in its social, political, and economic spheres. Elaborating on this point further, Bannerji states the following:

"Canada" then cannot be taken as a given. It is obviously a construction, a set of representations, embodying certain types of political and cultural communities and their operations. These communities were themselves constructed in agreement with certain ideas regarding skin color, history, language (English/French), and other cultural signifiers - all of which may be subsumed under the ideological category "white." (Ibid., 64)

The problematic stereotypes that are created about racialized groups in Canada contribute to the social construction of whiteness that permits white Canadians to maintain a specific place of privilege. Offering a historical and spatial analysis of how Canadian society and its laws were constructed on the foundations of a "white settler society," Sherene Razack (2002) describes how mythologies of Canada's origins paint a picture of white European settlers as the "bearers of civilization" and that people of colour arrived in this country after most of its development transpired. This myth promotes the idea of a Canadian national identity rooted in a systemic racial hierarchy that promotes whiteness and excludes racialized bodies and the histories of Indigenous peoples. It is through these national mytholo- 
gies, where European settlers become the bearers of civilization, that the racial state is made (Goldberg 2002). This process is deeply connected to the Canadian landscape and largely informs the racialized hierarchies that situate white settlers as fundamentally national subjects. Razack further contends that these myths are spatialized, and that each of these narratives work to prop up white European settlers as being entitled to this land and using the governing structures to make this law.

It is the production and reproduction of these myths, grounded in the disavowal of Indigenous peoples and people of colour, that permit white settlers to assert themselves as overseers of the nation. It is the white settlers who maintain positions of power that can organize their space, sustain unequal social relations, and in turn use these relations to shape racialized spaces. Through social and political means, they can then determine who can and cannot legitimately belong to the nation. Exposing the association between racialization and space is critical to analyzing space as a site of power relations. White Canadians obtain senses of selves through the construction of rigid boundaries that establish specific spaces as places reserved for national subjects.

Audrey Kobayashi and Linda Peake (2000) refer to the concept of "Geographies of Whiteness." They bridge critical race theory and geography by suggesting that place contextualizes the construction of race and the nation, generating geographically specific ideologies of racism and nationalism. Certain places assume more power than others by restricting or controlling spatial access. As an important site of power, the CAF is often an "overlooked form of national work and belonging" in academic and popular discourse (Cowen 2008, 20). The Canadian military is an important site of analysis because it is a crucial nerve centre for the formation of Canadian identity and the construction of the Canadian nation, notions that are deeply gendered and racialized. According to Kobayashi and Peake (2000), spatial interpretation needs to take into account "empty spaces" that result from silence, exclusion, and denial, and that serve as a basis for reproducing normative whiteness. Therefore, the bridging of geography and critical race theory offers a nuanced exploration of gendered and racialized individuals' experiences navigating life in the CAF.

\section{The Impact of Neoliberalism on the Racial- ized Soldier Subject}

A central feature of a racial state such as Canada is that it is often characterized as "colourblind" or "raceless" (Goldberg 2010). That is to say, the structural inequities are obscured by the neoliberal tenants of individualism and privatization. It becomes important, then, to trace how this colourblindess or raceless condition takes form and comes to have symbolic and material effects on people. David Goldberg (2010) asserts that colourblindness is a contemporary form of white supremacy constitutive of neoliberalism. Neoliberalism has been generally described as a set of top-down economic and political policies, whereby nation states should reject social welfare in favour of free-market capitalist policies geared towards the liberalization of trade regulations and tariffs, the deregulation of industry, privatization, deep cuts to social programs, and tax cuts to private and corporate interests (Harvey 2005, 13). I contend that diversity and inclusion policies and practices, particularly around race and racism, are extensions of this notion of colourblindness.

In the racial state, neoliberalism becomes visible when deconstructing and naming its strategies and characteristics. One of the tactics used is to suggest that everyone, regardless of social location, is equal and treated the same. Goldberg (2010) describes this strategy as "the national fantasy of homogeneity," where histories around colonial, racial, and gendered violence are deliberately forgotten or seen to have no bearing on the current understanding and imaginings of the nationstate formation (140). Quite effective, then, is the racial state's desire to avoid centering race or racial inequalities grounded in historical relations of domination. The result is a denial of history, a dehistoricization, and inequalities are then naturalized.

While much has been written about neoliberalism as a heightened capitalistic ideology, in this article, I am more concerned with neoliberalism as governmentality 
—relying on Foucauldian approaches that regard neoliberalism as a mentality of government (Barry, Osborne, and Rose 1996; Foucault 2008). Under neoliberalism, individual subjects are construed as entrepreneurs (Brown 2005) who surveille and work on themselves to better themselves. How racialized soldiers become entrepreneurial and moral subjects that are productive of good citizenry within the military industrial complex is key to understanding how white supremacy and neoliberalism operate at the level of the subject within militaries.

\section{Gender and Racial Diversity within the CAF}

The Canadian military's attempts to address diversity in its recruitment efforts is connected to historical and political struggles for justice, and the expansion of citizenship rights in the 1960s and 1970s. In fact, much of the political legislation of the period, as Deborah Cowen (2008) writes, "aimed to bring the federal government and public institutions in line with the values of multiculturalism, bilingualism and gender equity - values that were a core part of the Canadian 'rights' revolution" (160). Research on gender and the military in Canada has largely focused on the challenges to women's integration into the CAF (Davis 2020; Eichler 2016). Karen Davis (2020) argues that a central theme that has dominated much of the debate about the participation of women in Western military organizations is the relationship among gender, sex, and the "warrior" (37). In these debates, while sex refers to biological classification and assignment of people to male, female, and intersex categories, gender refers to the socially constructed norms, expectations, and roles associated with masculinity and femininity (Eichler et al. 2020). Gender is a primary way of organizing relationships of power in societies as well as in institutions such as the military. Significantly, this notion of the "warrior" is socially constructed as stereotypically male to the exclusion of those who present themselves outside the masculine warrior norm. In this context, women are constructed as the substandard warrior who compromises operational effectiveness.
In relation to CAF diversity and inclusion policy and initiatives, women have been primary targets for recruitment because of the need for more military labour and legislative changes. However, as Maya Eichler (2016) points out, even though legal barriers to women's full military integration in Canada were removed in 1989, women's social integration, especially in the combat arms, is still impacted by the powerful idea that soldiering centers on the construction of the male warrior (6). Consequently, women's representation in the CAF currently resides at $16 \%$ and remains uneven across the organization. Regarding their roles in the CAF, Davis (2013) has shown that women are concentrated in occupations that are stereotypically gendered such as in medical, dental, or clerical, and are often underrepresented in senior leadership. Other research has noted that the climate and culture of the military is unwelcoming and at times hostile towards women and LGBTQ members (Davis 2013; Gouliquer 2011). This is not all that surprising given the findings of the External Review into Sexual Misconduct and Sexual Harassment in the Canadian Armed Forces (The Deschamps Report) released in March 2015 that revealed a sexualized culture within the CAF. Former Justice Marie Deschamps stated in her report that the CAF is an "environment characterized by the frequent use of sexualized language, sexual jokes and innuendos, discriminatory comments with respect to the abilities of female members of the military and less serious but unwelcome sexual touching" (14) and noted that this sexualized culture contributes to "more serious incidents of sexual harassment and sexual assault" (Deschamps 2015, 21). This sexualized culture is rightly connected to the challenges surrounding women's integration into the CAF. This is a salient point as the diversity and inclusion of women in the CAF is not only about quantifiable representation of women, but it also requires a systemic cultural shift around gender relations.

In the 1980s, the Charter of Rights and Freedoms and the implementation of Employment Equity laws further pushed the military to diversify. With respect to racialized groups, specialized programs to recruit Indigenous soldiers into the CAF were long standing and have a complex history (Cowen 2008, 178). For ex- 
ample, the Oka crisis of 1990, an important moment for Indigenous resistance, marked a low point in Canada's military history and revealed its ongoing fraught relationship with Indigenous peoples whilst shining a bright light on the CAF's role in settler-colonial relations. Canada deployed almost 14,000 military personnel at the height of the crisis to quell the resistance (Cowen 2008). Throughout this turbulent period, the Canadian military continued to recruit Indigenous peoples, but did so cautiously and with minimal reference to the "Oka Crisis" and other Indigenous resistance (Edwards 2002). While the Oka crisis remains a contentious issue for Indigenous communities, the CAF nonetheless invests heavily in its recruitment campaigns targeting Indigenous communities.

Targeted recruitment among non-Indigenous racialized groups did not occur until the 1980s and the CAF did not have an official policy on racism until 1993. Cowen (2008) demonstrates that the Canadian Forces Personnel Applied Research Unit (CFPARU) was trying to grapple with the notion of ethnicity and how that would impact targeted recruitment. As Cowen explains, "Ethnicity was furthermore conceptualized as something of an obstacle to recruitment. It was constantly conflated with immigration status in CFPARU reports, as though they were interchangeable concepts, well into the 1990s" (Ibid., 170). A lack of engagement with racism in the ranks persisted even though there was a growing interest in recruiting racialized citizens. In fact, "the CFPARU initially attributed the low participation rates of people of colour in the military to the failings of their own cultures rather than the systemic racism or hegemonic whiteness of the military" (Ibid., 170). Cowen also explains that racialized groups were perceived as difficult to recruit because, in the words of the military, of a "built in resistance to any move that will take the youth away from the cultural group to which they belong" (CFPARU 1975a, cited in Cowen 2008, 170).

\section{Theoretical and Methodological Considera- tions}

This article is informed by critical race theory, feminist poststructuralist theory, and critical geography (Bhabha 1994; Cowen 2008; Kobayashi and Peake 2000; Minh-Ha 1995; Weedon 1997). From such a standpoint, an individual's subjectivity is made possible through the already gendered and racialized discourses to which he or she has access. I thus attempted to not only map the range of discourses to which racialized soldiers have access in constructing their meanings, but also to investigate how they position themselves in relation to these discourses. For example, there is a specific set of discourses for what it means to be a "good" and "loyal" soldier, which are articulated by individuals to define themselves as such. The discursive construction of what has been termed as the "military ethos" demarcates the boundaries within which soldiers can negotiate what it means to be a "good," "effective," and "dutiful" soldier within the military context. As a result, it is these discourses that subjects engage with when coming to understand themselves as soldiers. Deploying a "race cognizant poststructuralism" also means that I was interested in "constructions," a term that reflects the notion that reality is made and not found; racialized soldiers then construct "reality" through language and cultural practices. Drawing on Michel Foucault (1973), discourse refers not only to the meaning of language, but also to the real effects of language use. Discourses are regimes of truth and, as such, they specify what can be said or done at particular times and places, they sustain specific relations of power, and they construct particular practices. It is through discourse that meanings, subjects, and subjectivities are formed. Although discourse is not equivalent to language, choices in language point to those discourses being drawn upon by speakers and to the ways in which they position themselves and others. Like Chris Weedon ([1987] 1997), I understand that experience is given meaning in language and through a range of discursive formations that are often contradictory and that constitute conflicting versions of social reality.

The results of the qualitative study presented here draw 
from a larger study comprised of one-on-one semistructured interviews with a total of 30 retired or serving CAF members (17 men and 13 women) from the Toronto, Ottawa, or Halifax regions who identify as racialized. Results in this article reflect interviews with 5 of the 13 racialized women from various racial backgrounds (East Asian, South Asian, Caribbean, and African). The participants varied in age, rank, and commission status. Purposeful and snowball sampling techniques were used, and all the participants were approached through contacts with retired and reserve soldiers in the CAF (Babbie and Benaquisto 2002). The conversations with the participants occurred between 2013 and 2016 and lasted between one and three hours. For the purposes of this article, I have chosen to focus only on racialized women in order to explore the layered experiences of their lives and to illustrate the complexities of their identities. I also chose to focus on racialized women because they are often an ignored subpopulation with respect to research in the CAF. Through my interviews, I sought to understand how soldiers' racial and gendered positioning shapes their experience of the military, their relationship to military life, citizenship, and organized violence more broadly. I posed questions to explore the values placed on military service as a profession, what it means to be a soldier in the post $9 / 11$ era, their experiences with training and education on equity (for example, the military's Standard for Harassment and Racism Prevention Program and crosscultural pre-deployment training), and their encounters with various forms of oppression. Furthermore, I asked about their experiences of being a racialized subject in a predominantly white space and how they themselves constitute "diversity." Moreover, I asked questions about their nuanced encounters with racism with fellow soldiers, superiors, and civilians, in Canada and during their deployment overseas, to trace the complex expressions of whiteness operating in the Canadian military. The conversations were tape-recorded, transcribed, and then organized with the assistance of the QRS Nud*ist qualitative data analysis package. To ensure anonymity, self-chosen pseudonyms were used in the transcriptions and ensuing publications. Any information that could place the participants or identify them was also given a fictitious name to further protect the privacy and anonymity of the participants. In the remaining sections, I engage with racialized servicewomen's narratives as they make sense of their inclusion within the CAF.

\section{Joining the Military Family: Negotiating Racialized Femininity in the CAF}

In this section, I highlight how racialized servicewomen negotiate inclusion within the CAF. Several racialized women spoke about how and why they entered the CAF. Some approached recruitment centers on their own and others' curiosity was piqued at events where the military was present. In some cases, racialized women were motivated to join after $9 / 11$, while others needed employment and had very few options, if any, available to them in the Canadian job market. What is perhaps most striking is their desire to belong to and be an active, participating member of Canadian society. In some cases, the military afforded a semblance of purpose and belonging; in other soldiers' narratives, this notion of belonging is heavily critiqued. Here, Evelyn, a Chinese woman in the Reserve Force, and Lana, of mixed Asian descent, reflect on how they negotiated their identities and difference within the CAF:

Evelyn: When I first joined, I realized that being completely obedient is a good feature in the military. Chinese culture is different from Westernized culture...I guess traditional, Chinese culture is being obedient and as a female, being obedient, quiet, and listening to your elders, don't speak unless you're talked to, there's a rigid kind of mentality and I think that is engrained in me. So, when I turned to the military, I found it very, very natural and I excelled. And so, I see a lot of similar traits of how I grew up and my military experience.

Lana: As a female and being Asian, I think I fully stood out. Like, you notice people watching you. But I never felt like I was discriminated, no, but watched, yes. And I kind of just made a conscious effort to ignore it. If anything, I would be pointed out for being small and fe- 
male. So maybe my Asianness had something to do with it? Because we tend to be on the smaller side and then there's the assumption you can't perform as well, but I was definitely watched.

Both Evelyn and Lana are aware of their noticeable presence within the military through the function of the gaze on their respective bodies. The intersecting features of their identity around gender, race, and physical physique are expressed. In Evelyn's case, she speaks to the features of being Chinese and what is expected of her within Chinese culture. What is striking is how she is able to link elements of Chinese culture to what is expected from her in the CAF. She articulates that there is a connection between how she grew up and what was expected from her and how that connects to being a "good" soldier. The connections she draws from her Chinese culture, in terms of obedience, submissiveness, and listening to her elders, to the military culture itself appear to resonate with her and explain her ability to adapt.

Lana also articulates that she stood out but places an emphasis on her physique and being female, both gendered and racialized markers of identity grounded in stereotypes of Asian women. The association that Asian American women make between their features and personality characteristics stems directly from stereotypes created by dominant Western culture (Kaw 1993). Eugenia Kaw (1993) argues that "portrayals of Asian women through Western popular culture rarely deviate from stereotypical depictions and are often represented as dull, passive, hypersexualized, and nonsociable personalities often in the form of common stereotypes of China dolls, Geisha Girls or as the shy Polynesia beauty" (80). Presently, stereotypes of Asians as "model minorities" serve a similar purpose. This stereotype expands on older ones of passivity and dullness and has also expanded to refer to someone who is hard-working and technically skilled, but lacks creativity, sociability, and leadership. In Lana's case, her physique is constitutive of her gendered and racial make-up and this, in turn, is evaluated through the constant gaze that she receives, marking her questionable in her ability to perform her duties as a soldier.
The intersection of race and gender, on the one hand, requires paying attention to the nuances of difference. On the other hand, however, it also makes us aware of the larger relations of power in terms of the disciplinary function of the gaze that is experienced by these servicewomen. The persistence of the white male gaze and privilege is often experienced through relationships among colleagues, the military culture, policies, and CAF leadership. This power and prominence of the gaze is further illustrated in the following section.

\section{The White (Male) Gaze and Spaces of Whiteness}

In the interviews conducted for this research, encounters racialized women experienced across military life in the CAF should not be interpreted as isolated events, nor should they be divorced from historical influences. Below, Charlotte and Shannon's narratives demonstrate the significance of the racialized woman's body and how they are read in two distinct military spaces:

Charlotte: I remember my first posting and experience walking onto a garage floor. I was pumped because I had a female Captain. I remember walking down the garage floor in this huge hangar. I was in Transport, so on each side there were trucks lined up with mechanics working on and servicing them. When I first walked into the building - and her office was at the very back, so I had to walk across the hangar floor, I felt like all work stopped. And I don't know whether or not that was the case, but that was the feeling I got. All of a sudden, these sets of eyes were on me and I felt so closely examined for the first time in my life. And I don't know if it was being a woman or being of colour or both or what? Like the uniform, the combats are like olive grey and you don't look attractive in combats. No one does. Like, it's a uniform for a reason. They're supposed to erase all that, right? I felt like fresh meat walking down the hangar. I felt objectified. I felt like a streetwalker. I felt like I had 50 pairs of eyes on me. I felt icky and definitely not comfortable in my own skin. 
Charlotte, a retired Captain of mixed-race descent, recounts and theorizes the gaze upon her racialized and gendered body within an all-male, predominantly white space. In this particular instance, she feels that despite the function of the uniform, which is described as attempting to eliminate or reduce all difference, she remained starkly noticeable. Reflecting on this notion of the gaze or "the look," anti-colonial psychiatrist and scholar Franz Fanon (1967) states, "the movements, the attitudes, the glances of the other fixed me there" (112). Describing the objectifying nature of the gaze, he goes on to say, "Sealed into that crushing objecthood, the look imprisoned me" (Ibid., 113). While Charlotte is unsure whether it was her gender or race or a combination that made her the object of the white male gaze, she is made to feel objectified in that moment. Although she has a female Captain that she is excited to work with and report to, this does not influence how Charlotte is able to exist on a corporeal level in this space.

In the narrative below, the entrance of the Black female figure is received quite differently. As Nirmal Puwar (2004) states, "this [Black] presence is still capable of inducing a state of ontological anxiety, for it disturbs a particular "look'” (39). Shannon explains how her body was perceived during a run one morning while residing on a military base:

Shannon: I remember when I was jogging through the PMQs, which is the married quarters, and this little kid, maybe he was like 10 years old, but this white kid said to his friends, who were all white as well, says, "Oh, look, there goes a mommy niggy." It was just a surprise. These kids are just used to a homogeneous society because that's largely what the Canadian Forces is.

Tammy: Did you respond?

Shannon: No because I was shocked.... I just kept running but I remember looking at him strange. I saw he was a product of his parents, but you know, it was quick and I'm running, and in that moment, he says that to his friends.
It was almost like it was the first time that he saw somebody who wasn't white. For him, in front of his friends he was like, "Ah, look! There's a mommy niggy." Where would he even get that from except from his parents?

Shannon's racist and sexist encounter is startling, but not all together surprising in the larger context of anti-Black racism and the pervasive racism experienced by other soldiers of colour (George 2016). However, the utterance "There's a mommy niggy!" grabs one's attention, as if there is something to be seen, looked at, noticed, and observed. The entire scene is corporeal and felt viscerally by Shannon. In a similar vein, Fanon (1967) writes about his experiences when a little white boy "sees" him on the street:

"Look, a Negro!" I made a tight smile. "Look, a Negro!" It was true. It amused me. "Look, a Negro!" I made no secret of my amusement. "Mama, see the Negro! I'm frightened!" Frightened! Frightened! Now they were beginning to be afraid of me. I made up my mind to laugh myself to tears, but laughter had become impossible. I could no longer laugh because I already knew that there were legends, stories, history and above all historicity. (112)

Fanon (1967) observes that this look happens without verbal communication in various everyday spaces, including institutional spaces, and further demonstrates what this repetitive practice of "the look" does to the Black body. Puwar (2004) elaborates on Fanon's notion of the colonial gaze stating, "Empire was contemplated in such a way that its gaze put into play a corporeal racial schema of alien other(s) which helped to glue collectivities of whiteness with a superior sense of their 'natural' right to occupy privileged spaces of institutional representation on both a national and international scale" (40).

What is evident in Charlotte and Shannon's narratives is how female bodies of colour in the West signify meaning that is articulated through space (Mohanram 1999). The Black body is read by the dominant as rooted in other places, apart from respectable space, while whiteness remains unmarked and unnamed 
(Nelson 2008). Puwar (2004) explains "disorientation" as one of the processes that highlights the space-invader status of racialized bodies in privileged occupational positions:

The claims "black bodies" make on institutions by occupying spaces they are not expected to be in are constantly challenged by a look which abnormalises their presence and locates them, through the workings of racialized framings, belonging elsewhere. It is important to note though, that the black body is fixed by a white gaze, the white gaze itself is disoriented by the close proximity of these foreign bodies. (42)

I draw on Fanon and Puwar to illustrate how this colonial, racialized experience is not unusual. While Fanon writes of the colonial condition in the French colony of Martinique, his works helps to show that Charlotte's experience is part of an ongoing colonial gaze that marks racialized and gendered bodies as out of place. Similarly, Sara Ahmed (2000) examines the concept of strangeness to conceptualize how bodies are constituted as "Other" when they are "out of place" in neighbourhoods, institutions, or nations. She explains that "strange bodies are precisely those bodies that are temporarily assimilated as the unknown within the encounter: they function as the border that defines both the space into which the familiar body...cannot cross, and the space in which such a body constitutes itself as a home" (Ahmed 2000, 54). Therefore, in various contexts, but more specifically in the CAF, what becomes evident is that through the mechanism of the look or white male gaze, the racialized woman's body is rendered outside legitimate space, "its movement dictated by tacit rights of occupancy" and as such "cannot simply be" (Nelson 2008, 40). This is particularly instructive because the making of dominant subjects in spatial terms is contingent on how differently marked subjects take on disparate meanings through their ability to enter and remain in certain spaces.

\section{Fostering a Culture of Silence}

As previously discussed, currently, institutional racism is embedded through neoliberal policy and ethos. As a result, racism in the CAF manifests itself as a pervasive colourblindness. What this means is that it is difficult to address and name issues of race and racism in the CAF. Colourblindness operates by encouraging homogeneity and by blaming the individual, both of which lead to less accountability, the inability to name racism, and the discouraging of reporting. In this context, current diversity and inclusion initiatives perpetuate institutional racism in that they do not provide avenues to name the material and symbolic impacts of racism in the CAF. Goldberg (2010) argued that: "It is not that race is simply silenced, if silenced at all. It is shifted to less formal domains for the most part, embedded in structures, without being explicitly named, where it is more difficult to identify, more ambivalently related to, more ambiguous" (90). He goes on to suggest that because of this shift, "as race evaporates from the socio-conceptual landscape, racisms (in their plurality) are pushed further and further out of the sight, out of existence, unmentionable because the terms by which to recognize and reference them recede, fade from view and memory" (Goldberg 2010, 360). Consequently, this condition can permit racism to flourish and prevent detection by the general public (Goldberg 2010). Following Goldberg, I contend that racism and racial microaggressions remain embedded within the military structure and have been increasingly difficult to recognize. One of the main ways in which the discourse of silence operates around race and gender in the CAF is by redirecting blame onto soldiers themselves, where they are in effect responsible for their hardship and oppression because of their inability to "handle it" or "work it out." This was most visible through the claim of "playing the race card." My conversation with Liza illustrates this point:

Liza: I've thought many times about mentioning something about race. The problem is, every time you try to bring it up, someone is saying that I'm too sensitive or that I'm playing the race card or making a bigger deal of the issue than needs to be. If I have a problem with someone, it turns into me being the problem.

Suggesting that race and racism are factors in the CAF is often met with strong opposition, as evidenced by Liza's comments. Liza is accused of being "too sensit- 
ive" for even mentioning that race may be operating in a situation. This claim of sensitivity attributes qualities grounded in the feminine that are not conducive to being a "good" soldier. On the one hand, sensitivity is required by female soldiers in terms of being a good friend or confidante, but at the same time it is rebuked when the same soldier is trying to express a problem or concern. As my broader research has shown, this feminization of sensitivity also applies to male soldiers who suggest race and racism might be operating within the institution (George 2016). Consequently, this works to discredit racialized soldiers who may be also considered disloyal and unpatriotic for "rocking the boat." Behind the statement, "playing the race card," is the moral assertion that, within the CAF, grievances with respect to race are unmentionable. The assertion of the "race card" is not compatible within Canadian multicultural spaces. The very accusation of "playing the card" has become a way of disqualifying the attempt to discuss past and present racial injury (Williams 2001). Consequently, policing the use of the race card serves to discredit racialized suffering and is turned into an inconvenience. This tactic contributes to the culture of silence around racism and works to consolidate whiteness.

The servicewomen I interviewed often engaged in "mitigation strategies" which refer to "the processes through which individuals seek simultaneously to downplay or deny incidences of racism and to exonerate those accused of engaging in such acts. This involves offering alternative explanations with the purpose of refuting intentionality and responsibility on the part of the person(s) under scrutiny" (Burdsey 2011, 268). According to Ashley Doane (2006), these strategies of denial also reproduce colourblindness, relegating racism to an individual problem with individual solutions. Liza's narrative reveals the limits of institutional diversity and inclusion. If naming racism and injustice are seen as a personal problem with no recourse, then diversity can only ever be tokenistic and superficial, leaving the status quo intact.

\section{Conclusion: Doing Away with Diversity and Inclusion?}

Through an analysis of the ways in which racialized servicewomen in the CAF make sense of themselves and their experiences, it is evident that their "inclusion" is contingent on the white, patriarchal, colonial, and heteronormative structure that characterizes life in the contemporary CAF. Racialized servicewomen in my research study are living in a moment where they are marked by a striking paradox-one in which they are both targets and agents of racial and gendered violence. That is to say, within the CAF their experiences are at times fraught with sexism and racism, marking them as targets, but they are simultaneously also invited into imperial endeavours globally in order to sustain larger global structures of power.

This article asks to engage with the intersections of race and gender in the lives of racialized servicewomen, intersections that are often overlooked in discussions on diversity within the CAF. Complicating this notion of diversity, narratives reported here reveal that whiteness, hegemonic masculinity, and heteronormativity are integral to the military structure and culture and to daily negotiations of military life itself. It is impossible to separate identities as simply raced, sexed, gendered, or grounded in any singular marker of identity. The complexity of identities and experiences demand that we think through their operations as constitutive. What we see from these soldiers' experiences is that "diversity" in terms of current strategies and initiatives cannot mean anything beyond assisting racialized women to learn to function within an institution marked by larger systems of oppression.

If a national institution like the CAF continues to present strategies for inclusion in ways that only focus on the individual, the organization will fail structurally because it will not be able to respond to the unfamiliar and nuanced identities lived and experienced by its most marginalized members. Those marginalized through the interconnected issues of racism, sex- 
ism, and homophobia, in addition to other intersections of power, will continue to go unrecognized and be virtually erased by the institution. Diversity and inclusion initiatives, in their current form, are not able to capture the complex lived experiences of racialized servicewomen and will continue to serve as mere distractions. From the data presented here, these soldiers can always make concessions to belong and reproduce the status quo, but at what cost? According to Veterans Affairs Canada (VAC), women are more likely than men to report a difficult adjustment to civilian life. Based on a 2016 study, female veterans had higher odds of living with a disability, reported a lower quality of life than males, and had a higher prevalence of mental health conditions (Hachey et al. 2016). In 2017, VAC indicated that the ratio of female veterans who commit suicide compared with women in the Canadian general population is higher than for men, but they did not indicate what this means for racialized communities (Simkus et al. 2017). Most recently, Toronto Public Health has declared anti-Black racism a public health crisis (Boisvert 2020). Given these findings, diversity and inclusion work cannot be relegated to simply "image work" (Ahmed 2012), that is, work that makes an institution appear welcoming and diverse, where the words diversity and inclusion become ritualistic and continue to shield institutions from meaningful structural change. Racialized servicewomen's experiences within the CAF rupture the band-aid solutions that institutional diversity and inclusion initiatives reproduce, often creating the illusion of progress instead of meaningful social transformation.

\section{Endnotes}

1. I would like to acknowledge that some written parts and quotes from participants in this article are featured in and communicated in a previous publication with the University of Toronto Press. 


\section{References}

Ahmed, Sara. 2012. On Being Included: Racism and Diversity in Institutional Life. Durham, NC: Duke University Press.

Ahmed, Sara. 2000. Strange Encounters: Embodied Others in Post-Coloniality. London: Psychology Press.

Babbie, Earl, and Lucia Benaquisto. 2002.

Fundamentals of Social Research. Toronto: Thomson Canada Limited.

Bannerji, Himani. 2000. The Dark Side of the Nation: Essays on Multiculturalism, Nationalism and Gender. Toronto: Canadian Scholars Press.

Barry, Andrew, Thomas Osbourne, and Nichloas Rose. 1996. Foucault and Political Reason: Liberalism, Neoliberalism and Rationalities of Government. London: Routledge.

Bhabha, Homi K. 1994. The Location of Culture. London: Routledge.

Boisvert, Nick. 2020. "Toronto Board of Public Health Declares Anti-Black Racism a Public Health Crisis". CBC News Online. Retrieved from: https:// www.cbc.ca/news/canada/toronto/board-of-healthanti-black-racism-1.5603383.

Brown, Wendy. 2005. Edgework: Critical Essays on Knowledge and Politics. Princeton: Princeton University Press.

Burdsey, Daniel. 2011. “That Joke Isn't Funny Anymore: Racial Macroaggressions, Color-Blind Ideology and the Mitigation of Racism in English Men's First-Class Cricket." Sociology of Sport Journal 28 (3): 261-83.

Chief of Defence Staff. 2016. Canadian Armed Forces Diversity Strategy. Ottawa: Department of National Defence.
Cowen, Deborah. 2008. Military Workfare: The Soldier and Social Citizenship in Canada. Toronto: University of Toronto Press.

Crenshaw, Kimberlé. 1991. "Mapping the Margins: Intersectionality, Identity Politics, and Violence Against Women of Color." Stanford Law Review 43 (6): 1241-99.

Davis, Karen. 2020. "Negotiating Gender Inclusion." In Strengthening the Canadian Armed Forces through Diversity and Inclusion, edited by Alistair Edgar, Rupinder Mangat, and Bessma Momani, 36-51. Toronto: University of Toronto Press.

Davis, Karen. 2013. "Negotiating Gender in the Canadian Armed Forces 1970-1999.” PhD diss., Royal Military College.

Deschamps, Marie. 2015. External Review on Sexual Misconduct and Sexual Harassment in the Canadian Armed Forces. Ottawa: External Review Authority.

Doane, Ashley W. 2006. "What Is Racism? Racial Discourse and Racial Politics." Critical Sociology 32 (2/3): 255-74.

Edwards, V. 2002. "Don't Mention It! The Oka Crisis and the Recruitment of Aboriginal Peoples." Conference of Defence Associations Institute Student Conference Proceedings, Ottawa.

Eichler, Maya. 2016. "Learning from the Deschamps Report: Why Military and Veteran Researchers Ought to Pay Attention to Gender." Journal of Military, Veteran and Family Health 2 (1): 5-8.

Eichler, Maya, Yolande Bouka, Vanessa Brown, Nadège Compaoré, Tammy George, Andrea Lane, Leigh Spanner, and Victoria Tait. 2020. "GBA+ Toolkit." GBA+ Team of the Defense \& Security Foresight (DSF) Group. University of Waterloo. https://uwaterloo.ca/defence-security-foresight-group/.

Fanon, Franz. 1967. Black Skin, White Masks. New York: Grove Press. 
Foucault, Michel. 2008. The Birth of Biopolitics.

Basingstoke, UK: Palgrave Macmillan.

Foucault, Michel. 1973. The Birth of the Clinic: An Archaeology of Medical Perception. London: Tavistock.

George, Tammy. 2016. "Be All You Can Be or Longing to Be: Racialized Soldiers, Canadian Military Experience and the Im/Possibility of Belonging to the Nation." Unpublished PhD diss., University of Toronto.

Goldberg, David T. 2010. The Threat of Race: Racial Neoliberalism. Malden, MA and Oxford: Blackwell Publishing.

Goldberg. David T. 2002. The Racial State. Malden, MA and Oxford: Blackwell Publishing.

Gouliquer, Lynne. 2011. "Soldiering in the Canadian Forces: How and Why Gender Counts!" PhD diss., McGill University.

Hachy, Krystal K., Kerry Sudom, Jill Sweet, James M. Thompson, Mary Beth Maclean, and Linda D. VanTil. 2016. "Differences in Adjustment to Civilian Life between Male and Female Canadian Armed Forces Veterans." Res Militaris, ERGOMAS (2) Women in the Military Part Two: 1-12.

Harvey, David. 2005. A Brief History of Neoliberalism. Oxford: Oxford University Press.

Henry, Marsha. 2017. "Problematizing Military Masculinity, Intersectionality and Male Vulnerability in Feminist Critical Military Studies." Critical Military Studies 3 (2): 182-99.

hooks, bell. 2006. "Buddhism and the Politics of Domination." In Mindful Politics, edited by Melvin McLeod, 57-64. Somerville, MA: Wisdom.

Ito, Roy. 1984. We Went to War: The Story of Japanese Canadians Who Served During the First and Second World Wars. Toronto: University of Toronto Press.
Kaw, Eugenia. 1993. "Medicalization of Racial Features: Asian American Women and Cosmetic Surgery." Medical Anthropology Quarterly 7 (1): 74-89.

Kobyashi, Audrey, and Linda Peake. 2000. "Racism Out of Place: Thoughts on Whiteness and an Antiracist Geography in the New Millennium." Annals of the Association of American Geographers 90 (2): 392403.

Mensah, Joseph. 2010. Black Canadians: History, Experience, Social Condition. Halifax, NS: Fernwood Publishing.

Minh-Ha, Trinh.T. 1995. "Writing Postcoloniality \& Feminism.” In The Postcolonial Studies Reader, edited by Bill Ashcroft, Gareth Griffiths, and Helen Tifflin, 264-69. New York: Routledge.

Mohanram, Radhika. 1999. Black Body: Women, Colonialism, and Space. Minneapolis: University of Minnesota Press.

Nelson, Jennifer. 2008. Razing Africville: A Geography of Racism. Toronto: University of Toronto Press.

Price, Patricia L. 2010. "At the Crossroads: Critical Race Theory and Critical Geographies of Race." Progress in Human Geography 34 (2): 147-74.

Puwar, Nirmal. 2004. Space Invaders: Race, Gender, and Bodies Out of Place. Oxford: Berg.

Razack, Sherene. 2004. Dark Threats White Knights: The Somalia Affair, Peacekeeping, and the New Imperialism. Toronto: University of Toronto Press.

Razack, Sherene. 2002. Race, Space and the Law: Unmapping a White Settler Society. Toronto: Between the Lines.

Roy, Patricia E. 1978. “The Soldiers Canada Didn't Want: Her Chinese and Japanese Citizens." Canadian Historical Review 59 (3): 341-58. 
Simkus, Kristen, Linda VanTil, and David Pedlar.

2017. The 2017 Veteran Suicide Mortality Study: 1976

to 2012. Charlottetown, PEI: Veterans Affairs Canada

Research Directorate Technical Report.

Thobani, Sunera. 2007. Exalted Subjects: Studies in the Making of Race and Nation in Canada. Toronto:

University of Toronto Press.

Walker, James W. St. G. 1989. "Race and Recruitment in World War I: Enlistment of Visible Minorities in the Canadian Expeditionary Force." Canadian Historical Review 70 (1): 1-26.

Ware, Vron. 2012. Military Migrants: Fighting for YOUR Country. New York: Palgrave Macmillan.

Weedon, Chris. [1987] 1997. Feminist Practice and Poststructuralist Theory. London: Blackwell Press.

Williams, Linda. 2001. Play the Race Card:

Melodramas of Black and White from Uncle Tom to O.J. Simpson. Princeton: Princeton University Press. 